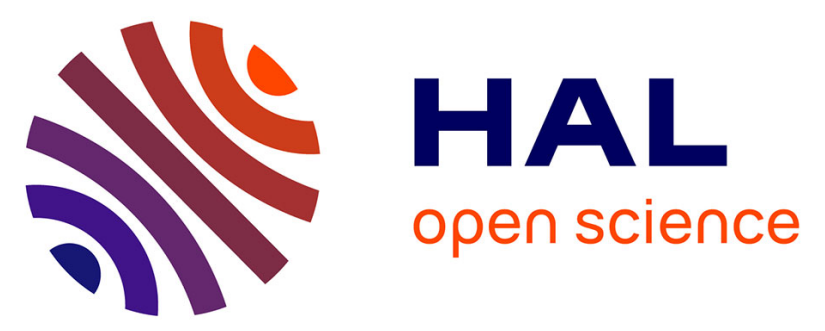

\title{
Impact of Trichogramma parasitoid age on the outcome of multiparasitism in the factitious host eggs of Chinese oak silkworm, Antheraea pernyi
}

Asim Iqbal, Yang-Yang Hou, Yong-Ming Chen, Asad Ali, Lucie S Monticelli, Nicolas Desneux, Lian-Sheng Zang

\section{To cite this version:}

Asim Iqbal, Yang-Yang Hou, Yong-Ming Chen, Asad Ali, Lucie S Monticelli, et al.. Impact of Trichogramma parasitoid age on the outcome of multiparasitism in the factitious host eggs of Chinese oak silkworm, Antheraea pernyi. Journal of Pest Science, 2020, 93 (4), pp.1347-1357. 10.1007/s10340020-01239-1 . hal-03285786

\section{HAL Id: hal-03285786 \\ https://hal.inrae.fr/hal-03285786}

Submitted on 13 Jul 2021

HAL is a multi-disciplinary open access archive for the deposit and dissemination of scientific research documents, whether they are published or not. The documents may come from teaching and research institutions in France or abroad, or from public or private research centers.
L'archive ouverte pluridisciplinaire HAL, est destinée au dépôt et à la diffusion de documents scientifiques de niveau recherche, publiés ou non, émanant des établissements d'enseignement et de recherche français ou étrangers, des laboratoires publics ou privés.

\section{(c)(1)}

Distributed under a Creative Commons Attribution| 4.0 International License 


\title{
Impact of Trichogramma parasitoid age on the outcome of multiparasitism in the factitious host eggs of Chinese oak silkworm, Antheraea pernyi
}

\author{
Asim Iqbal ${ }^{1} \cdot$ Yang-Yang Hou ${ }^{1} \cdot$ Yong-Ming Chen ${ }^{1} \cdot$ Asad Ali $^{2} \cdot$ Lucie S. Monticelli $^{3} \cdot$ Nicolas Desneux $^{3}$. \\ Lian-Sheng Zang ${ }^{1}$ (i)
}

Received: 30 December 2019 / Revised: 18 March 2020 / Accepted: 14 May 2020 / Published online: 30 June 2020

(c) Springer-Verlag GmbH Germany, part of Springer Nature 2020

\begin{abstract}
The age of Trichogramma parasitoids could influence biological traits which are of great importance for effectiveness of mass rearing systems. Recent studies demonstrated that Trichogramma ostriniae (TO) could parasitize Antheraea pernyi eggs through multiparasitism along with other Trichogramma species, although few adults could emerge successfully. It is important to characterize the factors modulating the performance of TO on A. pernyi eggs, notably in order to try enhancing its quantitative emergence through multiparasitism for further use in biological control. In this context, irrespective of host age, we tested different ages of TO females (from 0.5-day- to 6-day-old postemergence) in multiparasitism with Trichogramma chilonis (TC) on A. pernyi eggs. The results of the present study confirmed that TO parasitism on A. pernyi eggs was largely age dependent. Higher percentage of multiparasitism and higher number of emerged TO adults were recorded in the treatment where 3-day-old TO females were used for parasitization with TC on A. pernyi host. In addition, we also tested different female ratios of both Trichogramma species to find out an optimal ratio for use in mass production. The highest percentage of multiparasitism, emergence and optimum emerged number of TO (per A. pernyi egg) was observed with the ratio 3:2 (TO:TC) per 1 host egg. This study demonstrated that the age of TO females can significantly affect their performance in multiparasitism of large A. pernyi eggs. These results prompt for more research in order to develop an effective multiparasitism-based production of TO at the industrial scale.
\end{abstract}

Keywords Trichogramma chilonis $\cdot$ Trichogramma ostriniae $\cdot$ Biological control $\cdot$ Parasitoid development $\cdot$ Mass rearing

\section{Key messages}

- Few studies documented the factors affecting rearing of Trichogramma ostriniae on the large eggs of Chinese oak silkworm, A. pernyi.

Communicated by M. Traugott.

Lian-Sheng Zang

1sz0415@163.com

1 Engineering Research Center of Natural Enemies, Institute of Biological Control, Jilin Agricultural University, Changchun, China

2 Department of Agriculture, Abdul Wali Khan University, Mardan, Pakistan

3 University Côte d'Azur, INRAE, CNRS, UMR ISA, 06000 Nice, France
- We evaluated the impact of Trichogramma ostriniae age on multiparasitism with Trichogramma chilonis at different parasitoid ratios in A. pernyi eggs.

- The multiparasitism capability of Trichogramma ostriniae on A. pernyi host was dependent of parasitoid age, with 3-day-old parasitoid females showing highest performance on A. pernyi.

- Parasitoid female ratio of 3:2 (Trichogramma ostriniae: Trichogramma chilonis) per A. pernyi egg was found optimal for potential mass rearing. These results provide useful information about mass production of two Trichogramma species using multiparasitism method.

\section{Introduction}

The Trichogrammatidae family consists of about 650 parasitoid species from which some have been successfully used against numerous insect pests for over 100 years (Smith 
1996; Tabone et al. 2010; Yuan et al. 2012; Chailleux et al. 2013; Du et al. 2017; Guo et al. 2019; Zang et al. 2021). These parasitoids are key biological control agents against various agricultural pests in China (Zang et al. 2021). Among these, Trichogramma ostriniae Pang \& Chen is abundant and used against Asian corn borer Ostrinia furnacalis Guenee (Lepidoptera: Crambidae) since the early 1950s (Gardner et al. 2012; Li et al. 2018; Zang et al. 2021).

Ostrinia furnacalis is a key economic pest of corn in China, causing an average of 6-9 million tons yield losses per year (Wang et al. 2014). Currently, about 5.5 million hectares of corn fields are treated annually with $T$. ostriniae, T. chilonis Ishii, T. dendrolimi Matsumura and other Trichogramma species across northeastern China (Zang et al. 2021). Inundative releases of $T$. ostriniae against O. furnacalis in corn are on average 75,000-120,000 per hectare, and result in over $90 \%$ parasitism and successful control of the pest (Wang et al. 2000).

Trichogramma ostriniae is a key biological control agent for $O$. furnacalis in China and is usually mass-produced on rice moth Corcyra cephalonica Stainton (Lepidoptera: Pyralidae) eggs. However this host is not cost effective owing to the small size of eggs that could support the development of only one parasitoid per egg (Liu et al. 1998). In addition, the quality of these eggs for parasitoid rearing declines when the eggs are stored for more than 2-3 weeks (Wang et al. 1998; Wu et al. 2018). Another biological control agent, Trichogramma chilonis, can be mass-produced on eggs of Chinese oak silkworm, Antheraea pernyi GuérinMéneville (Lepidoptera: Saturniidae) (Wang et al. 2005). Currently, A. pernyi is considered as the best factitious host for the mass production of Trichogramma parasitoids because of high parasitism rate, low cost of production, and easy to store and transport (Huang et al. 2013; Zang 2015; Zhang et al. 2017, 2018; Zang et al. 2021). Due to their large size, A. pernyi eggs can enable 60-260 Trichogramma adults to be produced per host egg (Zang et al. 2021). Although A. pernyi host eggs are widely accepted, they also come across some limitations where thick and hard chorion is one of these limitations. Several Trichogramma species like T. embryophagum Hartig, T. evanescens Westwood, T. brassicae Bezdenko and T. piceum Dyurich could parasitize A. pernyi eggs but they often fail to chew an emergence hole (Hassan et al. 2004). This failure is due to the thick and hard chorion of A. pernyi eggs; parasitoid adults are trapped inside the host egg and they die. Trichogramma ostriniae is one of the key species that faces these limitations (Li et al. 2018).

The oviposition behavior of parasitoids is an important component in their biology which determines their role in ecosystems and their economic importance (Reznik et al. 2001; Wang et al. 2019). Parasitoid species having all of their egg complement mature upon emergence are referred as pro-ovigenic, while those that do not are syn-ovigenic; egg maturation strategies are related to parasitism mode (Jervis et al. 2001). Trichogramma ostriniae are among syn-ovigenic parasitoids, carrying only a fraction of mature eggs in ovaries after emergence, and egg maturation tends to increase as the age increases till 3rd day of adult life (Chen et al. 2005). Li et al. (2018) reported multiparasitism of $T$. ostriniae (newly emerged $<8 \mathrm{~h}$ ) with $T$. dendrolimi on $A$. pernyi host. Their results confirmed that $T$. ostriniae can multiparasitize $A$. pernyi eggs but only few adults were able to emerge per host egg. Therefore, in the context of possible development of mass production of $T$. ostriniae using a multiparasitism-based method, further experiments are needed to evaluate how factors such as parasitoid age could modulate emergence rate from $A$. pernyi host (during multiparasitism). Several studies demonstrated that Trichogramma parasitoid age could impact parasitism and progeny emergence from different host eggs in monoparasitism (Garcia et al. 2001, Hegazi and Khafagi 2001; Hohmann and Luck 2004; Makee 2005; Ayvaz et al. 2008; Pizzol et al. 2012). However, parasitoid developmental rates and agerelated oviposition patterns (syn-ovigenic or pro-ovigenic) could also have influence on the outcomes of multiparasitism between parasitoids (Cusumano et al. 2012; Harvey et al. 2013). Multiparasitism occurs when an already parasitized host is attacked again by a parasitoid of the same or different species (Yamamoto et al. 2007; Desneux et al. 2009; Harvey et al. 2009; Keinan et al. 2012; Harvey et al. 2013; Velzen et al. 2016). In a previous study we demonstrated that rearing host species significantly affected the outcomes of multiparasitism between egg parasitoids (Iqbal et al. 2019). Parasitoids reared on large host eggs produced more progeny in multiparasitism as compared to small host-reared parasitoids. However, it remains unclear whether parasitoid age could have an impact on multiparasitism. Published literature lacks the information related to the effect of parasitoid age on multiparasitism; therefore, to our knowledge, this study is the first to evaluate these aspects.

Trichogramma chilonis is among the few parasitoids which can efficiently be mass reproduced on A. pernyi eggs through monoparasitism. The most abundant parasitoid species attacking eggs of $O$. furnacalis are $T$. ostriniae, $T$. dendrolimi and T. chilonis which are distributed throughout China (Wang et al. 2005). A previous study indicated that T. dendrolimi exhibited higher adaptation to host eggs of A. pernyi than T. ostriniae mostly during multiparasitism, where interspecific competition inside the large egg could significantly suppress $T$. ostriniae ( $\mathrm{Li}$ et al. 2019). Therefore, to test the hypothesis that parasitoid age affects the outcome of multiparasitism, we selected T. chilonis to test in multiparasitism with $T$. ostriniae. Here, we evaluated different age limits (in days) of $T$. ostriniae in multiparasitism with T. chilonis to shed light on the impact of T. ostriniae age on 
parasitism of A. pernyi host. We also tested different female ratios of both species to identify optimal ratio for application in mass production system. The present study provides useful information on possible methods for $T$. ostriniae industrial production, and potential further use against $O$. furnacalis (and other lepidopteran pests).

\section{Materials and methods}

\section{Parasitoids}

Egg parasitoids T. chilonis (TC) and T. ostriniae (TO) were collected in 2011 from rice fields using sentinel egg masses of rice striped stem borer, Chilo suppressalis Walker (Lepidoptera: Crambidae) in Changchun, Jilin province, China. Trichogramma species were identified from male genital capsule using electronic microscope micrograph and were further confirmed by sequence analysis of rDNA-ITS2 (GeneBank Accession Nos. of FR828481 and FR750277 for TO and TC, respectively) (Pinto 1992; Stouthamer et al. 1999). Under laboratory conditions $25 \pm 1{ }^{\circ} \mathrm{C}, 65 \pm 5 \% \mathrm{RH}$ and a 14:10 (L:D) photoperiod, the rearing of both parasitoid species was carried out on C. cephalonica eggs for several generations. Parasitoids and host voucher specimens were preserved in the Institute of Biological Control, Jilin Agricultural University, Changchun, Jilin province, China.

\section{Chinese oak silkworm host}

Cocoons of Chinese oak silkworm A. pernyi were collected from Yongji city (Jilin Province, China) and were shifted to Institute of Biological Control, Jilin Agricultural University in December 2018. Cocoons were stored till February 2019 for near 3 months at temperature of $-4{ }^{\circ} \mathrm{C}$. Then, the cocoons were hanged in emergence rooms for incubation at a temperature of $25 \pm 1{ }^{\circ} \mathrm{C}$. Mature and unmated female moths of $A$. pernyi were collected after emergence from cocoons and were kept for $2-3$ days at a temperature of $4{ }^{\circ} \mathrm{C}$ in refrigerator. Host eggs for experiments were collected by dissecting the abdomen of mature female moths, washed with distilled water and were kept under room temperature to dry. Immature greenish eggs were removed, and healthy large eggs were collected for experiments after they became dry. Five large eggs of $A$. pernyi collected within $8 \mathrm{~h}$ were then pasted using non-toxic glue on a strip-shaped egg card $(5 \mathrm{~cm} \times 0.5 \mathrm{~cm})$ and were used in the experiments.

\section{TO age impact in multiparasitism with TC on $A$. pernyi host}

Parasitoid colonies were raised on C. cephalonia eggs under laboratory conditions of $25 \pm 1{ }^{\circ} \mathrm{C}, 65 \pm 5 \% \mathrm{RH}$ and a $14: 10$
(L:D) photoperiod. Trichogramma ostriniae (both male and female) emerged from $C$. cephalonica eggs were kept in a glass tube of $3.5 \mathrm{~cm}$ in diameter and $10 \mathrm{~cm}$ long to reach the various ages, i.e., 0.5-, 1-, 2-, 3-, 4-, 5- and 6-day-old postemergence without host eggs. All adult parasitoids were fed with drops of $20 \%$ honey solution till they were used in the experiments. Trichogramma chilonis wasps emerged within 12-h from C. cephalonica eggs were used in all experiments. The same age TC wasps were used throughout experiments, because regardless age factor TC can parasitize $A$. pernyi eggs and can emerge successfully under monoparasitism.

Specific wasp ratio having twenty-five TO females and five TC females [25:5 (TO:TC)] per replicate were used to evaluate the parasitism capability of different ages of TO females in multiparasitism with TC on A. pernyi large host eggs. Different ages TO females and 0.5-day-old TC females were introduced simultaneously into glass tube of $3.5 \mathrm{~cm}$ in diameter and $10 \mathrm{~cm}$ long, containing five host eggs of A. pernyi (host eggs were pasted $1 \mathrm{~cm}$ apart on a strip-shaped card with the help of non-toxic glue). Five host eggs were kept constant throughout all experiments. Both Trichogramma species were allowed to parasitize $A$. pernyi eggs for $48 \mathrm{~h}$ under laboratory conditions. After wasp removal, parasitized eggs of $A$. pernyi were cut out individually and each egg was enclosed in a glass tube held in incubation chamber per conditions already defined for laboratory rearing till parasitoids developed. After 6-7 days of wasp removal, the $A$. pernyi eggs held in incubation chamber changed its chorion color from pure white to dark gray, where these eggs were considered as multiparasitized by TO and TC. Further confirmation of multiparasitized eggs was made at the time of wasp emergence per egg. Test for each age limit of TO was repeated 10 times in multiparasitism with TC. Total of 250 females of TO, 50 females of TC and $50 \mathrm{~A}$. pernyi host eggs were tested in 10 replications for each age limit experiment.

\section{Screening of different wasp to wasp ratios of both Trichogramma species in multiparasitism on $A$. pernyi}

Different ratios of females of both Trichogramma species were tested in order to optimize emergence of TO from $A$. pernyi eggs in multiparasitism. In these experiments, all the TO female wasps used were 3-day-old postemergence (higher parasitism rate of $A$. pernyi, reported here in results section) and TC female wasps were 12-h-old postemergence. Different tested ratios were 15:10 (TO:TC), 20:10 (TO:TC) and 25:5 (TO:TC). For each ratio test, female wasp of TO and TC was introduced simultaneously into glass tube of $3.5 \mathrm{~cm}$ in diameter and $10 \mathrm{~cm}$ long, containing five host eggs of A. pernyi (host eggs were pasted $1 \mathrm{~cm}$ apart on a strip-shaped card with the help of non-toxic glue). Test for 
each ratio was repeated 15 times. The rest of the procedure was the same as mentioned above for the TO age evaluation experiments.

\section{Studied parameters}

The percentage of multiparasitism was documented as the number of eggs multiparasitized/total number of eggs offered $\times 100$. The percentage of multi-species emergence for each ratio was documented as the number of eggs with holes/total number of parasitized eggs $\times 100$. Total number of adults emerged per $A$. pernyi egg were recorded for each species. Total number of adults emerged for TO and TC per A. pernyi were also recorded. Developmental times were recorded as the number of days from parasitism to adult wasp emergence. At end, parasitized eggs from which no wasp emerged were dissected and pupae per egg, dead wasps inside egg were recorded under microscope. The emergence holes on the surface of egg were also recorded.

\section{Data analysis}

In all those treatments where different age limits of TO were used in multiparasitism with TC, comparison of percentages of multiparasitized eggs, the developmental time of two species, the number of emerged adults for specific species per egg and their female progeny, and the number of parasitoids of both species emerging from the same egg of the host was performed by using a one-way ANOVA (SAS Institute 2010); where recorded data for all the parameters showed significant differences among all treatments in ANOVA, the mean numbers of all the parameters were compared among the tested ratios using Tukey's honestly significant difference (HSD) test $(\alpha=0.05)$. Before an ANOVA was performed, the percentages of multiparasitized eggs, adult emergence, and female progeny were arcsine $\sqrt{ } x$ transformed to homogenize variances and were subjected to Shapiro-Wilk test. The same analysis was done for experiment where different female ratios were tested.

\section{Results}

\section{TO age impact in multiparasitism with TC on $A$. pernyi host}

Parasitoid age significantly affected parasitism of TO in multiparasitism conditions with TC on A. pernyi $\left(F_{6,63}=29.101\right.$; $P<0.0001$; Fig. 1$)$. The treatments where 0.5-day-, 1-dayand 2-day-old TO females were used for parasitizing $A$. pernyi eggs with TC showed significantly lower percentages of multiparasitism (20\%, 22\% and 28\%, respectively) than when 3-day- and 4-day-old females were used $(76 \%$ and $72 \%$, respectively). The percentages of multiparasitism were decreased to $40 \%$ and $12 \%$ in the treatments where 5-day- and 6-day-old TO females were used for parasitization, respectively.

The percentages of multi-species emergence in all the treatments were similar $\left(F_{6,63}=0.387 ; P=0.8844\right.$; Fig. 1$)$. The percentage of emergence in all treatments was dependent on TC species, where the same number of TC females was offered in all treatments in multiparasitism.
Fig. 1 Mean percentage $( \pm$ $\mathrm{SE}$ ) of multiparasitism and multi-species emergence from A. pernyi eggs for different Trichogramma ostriniae (TO) age treatments (0.5-day- to 6-day-old). Trichogramma chilonis (TC) age was 0.5-day-old. Lowercase and capital letters indicate significant differences among the treatments (Tukey's HSD test, $P<0.05$ )

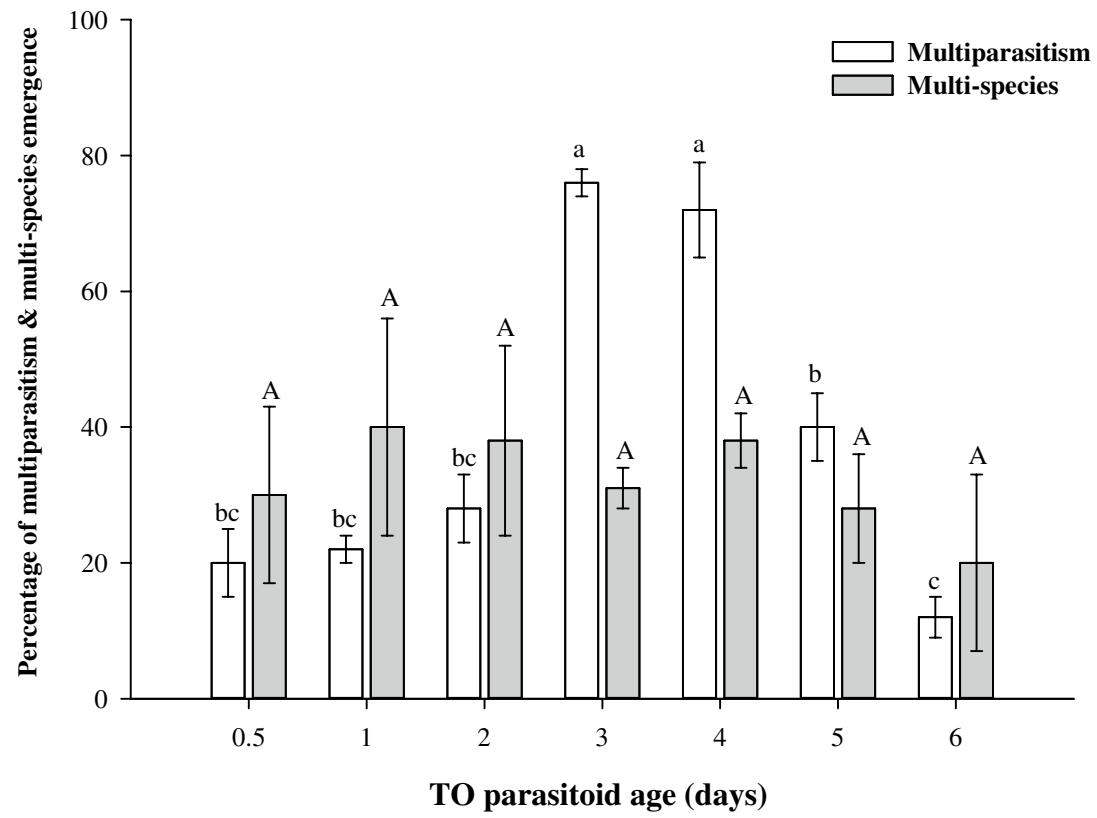


Similar to multiparasitism, number of emerged TO offspring per A. pernyi egg showed significant differences in all treatments where various age limits of TO females were used for parasitizing $A$. pernyi host during multiparasitism with TC $\left(F_{6,40}=4.558 ; P<0.0001 ;\right.$ Fig. 2$)$. Significantly high number (29.50) TO offsprings emerged per A. pernyi egg in the treatment where TO females used for parasitism had an age limit of 3-day-old. That's why we selected TO females 3-day-old age limit in the second set of experiments. No TO offspring emerged per $A$. pernyi egg in the treatment where the TO females used for parasitizing had an age limit of 0.5-day-old. The emerged offspring number of TC per A. pernyi egg was similar among all the treatments $\left(F_{6,40}=1.351 ; P=0.2579 ;\right.$ Fig. 2$)$. Furthermore, significant differences were found in the number of parasitoids of both species emerging from the same host egg among the treatments $\left(F_{6,40}=4.014 ; P=0.0001 ;\right.$ Fig. 2$)$.

\section{Screening of different wasp to wasp ratios of both Trichogramma species on A. pernyi host under multiparasitism}

\section{Parasitism and emergence rate}

No significant differences were found when comparing percentage of multiparasitism among the tested ratios $\left(F_{2,42}=2.549\right.$; $P=0.0902$; Fig. 3). Percentage of multispecies emergence showed significant differences among the tested ratios $\left(F_{2,42}=7.764 ; P<0.0001 ;\right.$ Fig. 3$)$. Significantly highest percentage of multi-species emergence of $71 \%$ was recorded in the treatment where wasps to wasps ratio was 15:10 (TO:TC). Significantly lower percentages of multi-species emergence were recorded in the treatments where wasps to wasps ratios were 20:10 (TO:TC) and 25:5 (TO:TC) (49\% and 40\%, respectively).

\section{Emerged wasps per A. pernyi egg}

The number of TC adults emerged per A. pernyi egg showed significant differences in multiparasitism with TO among the tested ratios (Table 1). The total offspring emerged for TC in the tested wasp to wasp ratios 15:10 (TO:TC), 20:10 (TO:TC) and 25:5 (TO:TC) were 36.62, 29.81 and 27.18, respectively $\left(F_{2,76}=4.869 ; P<0.0001\right)$. For TO, emerged offspring numbers did not show significant differences when comparing the mean values among tested wasp to wasp ratios (Table 1). The total emerged TO offsprings per $A$. pernyi egg were $22.08,25.13$ and 26.36 for the ratios $15: 10$ (TO:TC), 20:10 (TO:TC) and 25:5 (TO:TC), respectively $\left(F_{2,76}=0.804 ; P=0.4514\right)$.

The total number of adult wasps of both species emerging from the same A. pernyi egg also did not show significant differences in all tested wasp to wasp ratios $\left(F_{2,76}=1.286\right.$; $P=0.2824$; Table 1). The total number of adult wasps of both species emerging from the same A. pernyi egg in the wasp to wasp ratios of 15:10 (TO:TC), 20:10 (TO:TC) and 25:5 (TO:TC) were 58.70, 54.94 and 53.54, respectively. When emergence of parasitoids from A. pernyi eggs accomplished, dissection of eggs was carried out under microscope to record inside egg data. The total number of immature pupa (unidentified) inside per egg showed significant differences among the tested ratios $\left(F_{2,42}=8.093 ; P<0.0001\right.$;
Fig. 2 Mean number $( \pm$ SEs) of parasitoids emerged per egg (per species and in total) for different Trichogramma ostriniae (TO) age treatments $(0.5$ day- to 6-day-old). Trichogramma chilonis (TC) age was 0.5-day-old. Lowercase, capital and italic letters indicate significant differences among the treatments (Tukey's HSD test, $P<0.05)$

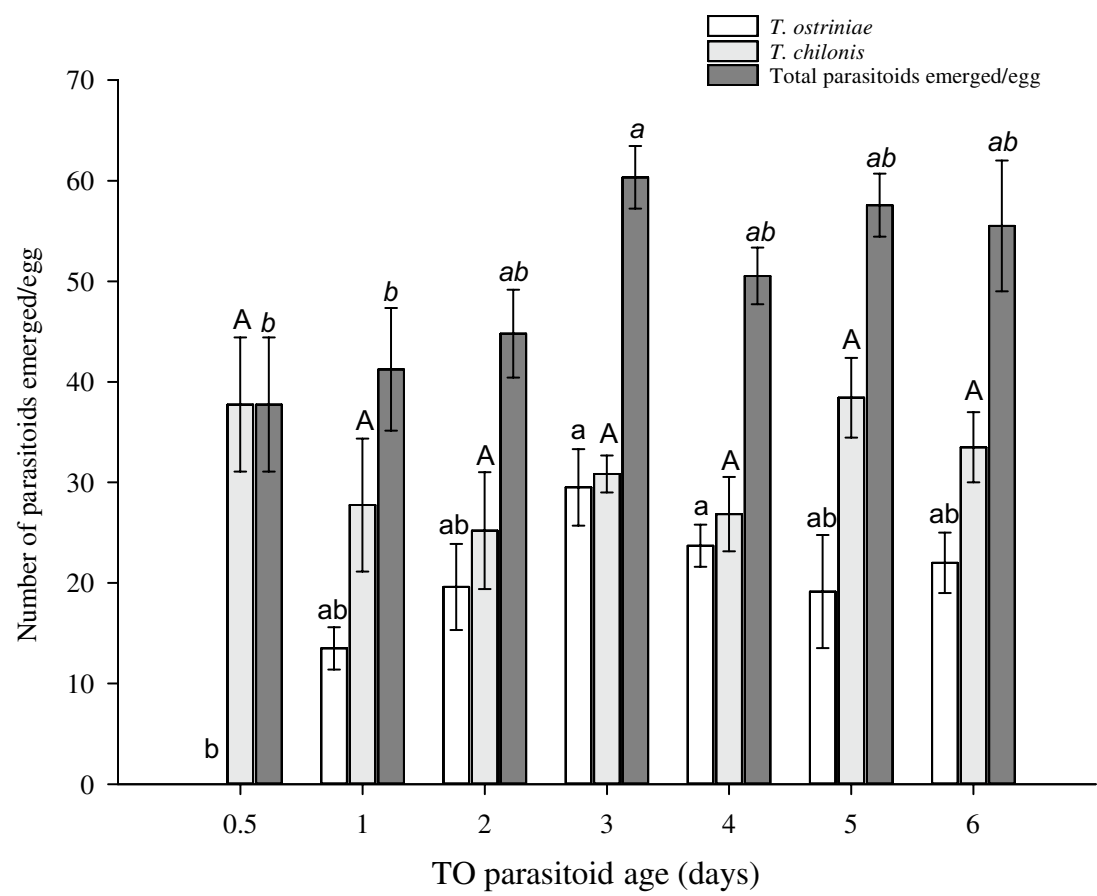


Fig. 3 Mean percentages $( \pm S E)$ of multiparasitism and multispecies emergence from $A$. pernyi eggs for different wasp to wasp ratios (Trichogramma ostriniae (TO):Trichogramma chilonis (TC)). Lowercase and capital letters indicate significant differences among the tested ratios (Tukey's HSD test, $P<0.05$ )

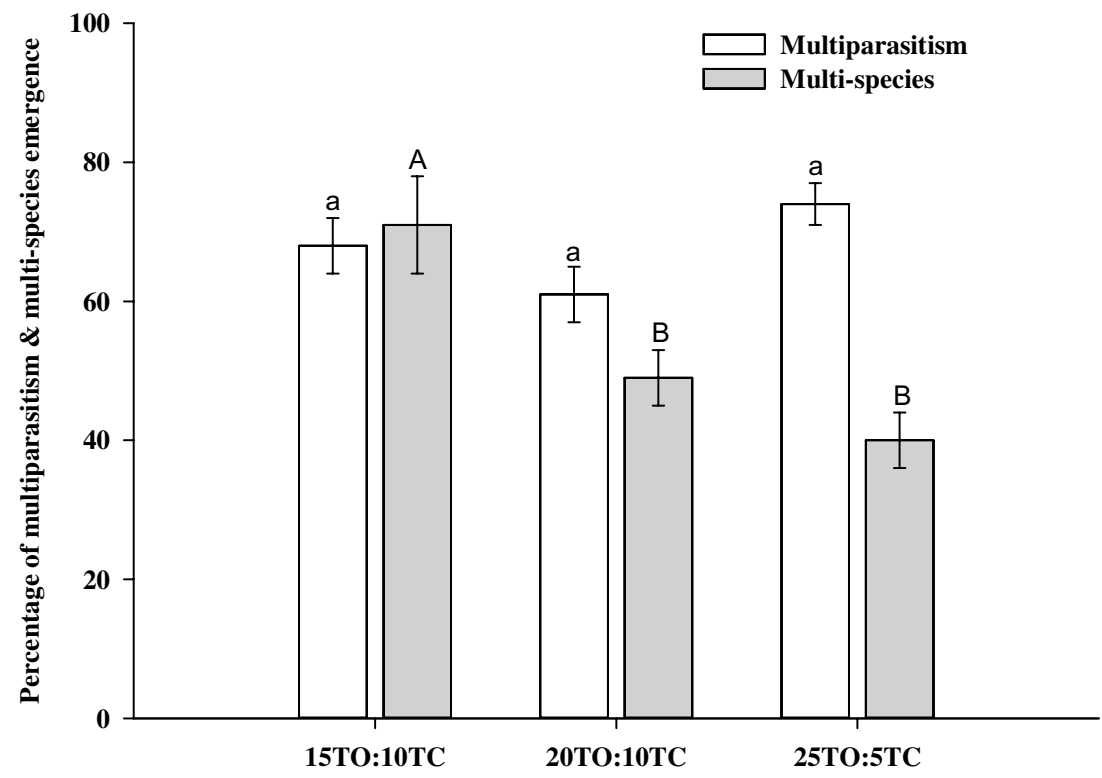

Different wasp to wasp ratios in multiparasitism
Table 1 Different biological parameters of Trichogramma ostriniae (TO) and T. chilonis (TC) multiparasitizing Antheraea pernyi eggs

\begin{tabular}{lcrrr}
\hline Parameters & \multicolumn{4}{l}{$\begin{array}{l}\text { Different wasp ratios of both Trichogramma } \text { species in } \\
\text { multiparasitism }\end{array}$} \\
\cline { 3 - 5 } & & \multicolumn{1}{c}{15 TO:10TC } & 20 TO:10TC & \multicolumn{1}{c}{25 TO:5TC } \\
\hline No. of emerged TO and TC/egg & TO & $22.08 \pm 2.50 \mathrm{a}$ & $25.13 \pm 2.33 \mathrm{a}$ & $26.36 \pm 2.61 \mathrm{a}$ \\
& TC & $36.62 \pm 2.28 \mathrm{a}$ & $29.81 \pm 2.11 \mathrm{ab}$ & $27.18 \pm 2.25 \mathrm{~b}$ \\
Development rate & TO & $12.82 \pm 0.40 \mathrm{a}$ & $13.15 \pm 0.14 \mathrm{a}$ & $12.57 \pm 0.12 \mathrm{a}$ \\
& TC & $12.60 \pm 0.18 \mathrm{a}$ & $12.71 \pm 0.15 \mathrm{a}$ & $12.32 \pm 0.09 \mathrm{a}$ \\
Average dead wasps/egg & TO & $8.45 \pm 2.73 \mathrm{~b}$ & $14.50 \pm 2.29 \mathrm{ab}$ & $17.93 \pm 2.49 \mathrm{a}$ \\
& TC & $2.84 \pm 1.41 \mathrm{a}$ & $3.39 \pm 1.07 \mathrm{a}$ & $3.16 \pm 0.85 \mathrm{a}$ \\
Female rate & TO & $0.82 \pm 0.00 \mathrm{a}$ & $0.80 \pm 0.00 \mathrm{a}$ & $0.81 \pm 0.01 \mathrm{a}$ \\
& TC & $0.85 \pm 0.00 \mathrm{a}$ & $0.83 \pm 0.00 \mathrm{a}$ & $0.85 \pm 0.01 \mathrm{a}$ \\
Total no. of wasp emerged & & $58.70 \pm 2.36 \mathrm{a}$ & $54.94 \pm 2.32 \mathrm{a}$ & $53.54 \pm 2.60 \mathrm{a}$ \\
\hline
\end{tabular}

3-day-old TO with 0.5-day-old TC. For each parameter, means \pm SEs are reported. Each value followed by different lower-case letters was significantly different among the tested ratio treatments (Tukey's HSD test, $P<0.05)$
Fig. 4A). Significantly less number 1.17 of immature pupa per A. pernyi egg was recorded for the wasp to wasp ratio 15:10 (TO:TC). Significantly high numbers 3.22 and 4.07 of immature pupae per A. pernyi egg were recorded for the ratios 20:10 (TO:TC) and 25:5 (TO:TC), respectively. Similarly, significant different numbers of dead adults were found per egg among the tested wasp to wasp ratios, specifically for the TO species $\left(F_{2,42}=3.645 ; P<0.0001\right.$; Table 1$)$. The numbers of dead wasps per egg for TO species were 8.45 , 14.50 and 17.93 in the tested wasp to wasp ratios $15: 10$ (TO:TC), 20:10 (TO:TC) and 25:5 (TO:TC), respectively. The number of dead adults per egg recorded for TC was statistically similar among all of the tested wasp to wasp ratios $\left(F_{2,42}=0.058 ; P=0.9436\right)$ (Table 1$)$.
Pre-emergence time of both species did not show significant differences in all the tested wasp to wasp ratios (Table 1). Pre-emergence time for TO species was 12.82, 13.15 and 12.57 days in the ratios 15:10 (TO:TC), 20:10 (TO:TC) and 25:5 (TO:TC), respectively $\left(F_{2,74}=0.674\right.$; $P=0.5127)$. Similarly, the pre-emergence time for TC was $12.60,12.71$ and 12.32 days in the ratios 15:10 (TO:TC), 20:10 (TO:TC) and 25:5 (TO:TC), respectively $\left(F_{2,75}=1.26\right.$; $P=0.2896)$.

Furthermore, the female rates of emerged offsprings for both parasitoid species in multiparasitism showed no significant differences (Table 1). The offspring population of TO emerging from $A$. pernyi eggs always showed at minimum $80 \%$ of females in all tested wasp to wasp ratios 

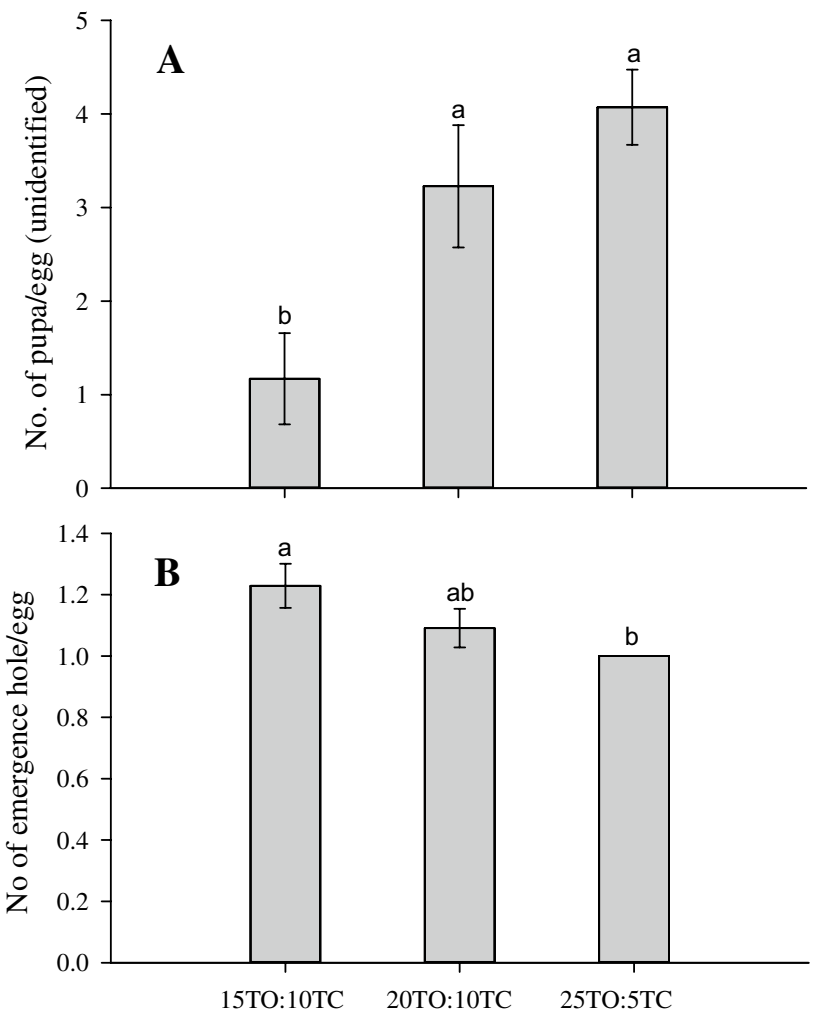

Different wasp to wasp ratios in multiparasitism

Fig. 4 A mean number ( \pm SEs) of pupa, and B mean number $( \pm$ SEs) of emergence holes per host egg among different wasp to wasp ratios (Trichogramma ostriniae (TO):Trichogramma chilonis (TC)). Lowercase letters indicate significant differences among the tested ratios (Tukey's HSD test, $P<0.05$ )

$\left(F_{2,74}=0.674 ; P=0.5127\right)$. Similar results were observed for TC $\left(F_{2,75}=1.26 ; P=0.2896\right)$ (Table 1$)$. Emergence holes made by Trichogramma parasitoids on the surface of $A$. pernyi egg showed significant differences in numbers among the tested ratios $\left(F_{2,76}=3.541 ; P<0.0001\right.$; Fig. 4B). Significantly highest number (1.22) of emergence holes per egg was recorded for the 15:10 (TO:TC). Significantly lower numbers 1.09 and 1.00 of emergence holes per egg were recorded for 20:10 (TO:TC) and 25:5 (TO:TC) ratios, respectively.

\section{Discussion}

Parasitoids are often involved in extrinsic and/or intrinsic competitive interactions (Cusumano et al. 2012), including in mass rearing conditions (e.g. in Trichogramma parasitoids, Zang et al. 2021). We demonstrated that two parasitoid species, TO and TC, can parasitize succesfully the large egg host, $A$. pernyi, through multiparasitism, and particular conditions were identified to maximize parasitoid production in such condition (e.g. wasp to wasp ratios and optimal parasitoid age). These results match with our previous study (Iqbal et al. 2019) reporting multiparasitism of T. leucaniae Pang $\&$ Chen and TC, and in which we suggested that both parasitoid species can be mass reared on $A$. pernyi through multiparasitism. Similarly, Li et al. (2018) reported multiparasitism of TO and T. dendrolimi on A. pernyi, with T. dendrolimi presence increasing the emergence rate of TO from this host. In overall, parasitoid species sharing the same host sources can be involved in multiparasitism, and this appears being common in egg parasitoids (Yamamoto et al. 2007; Mandour et al. 2008; Cabello et al. 2011; Cusumano et al. 2016).

\section{Trichogramma ostriniae age impacts on multiparasitism}

The age of $T$. ostriniae females had an impact on the outcome of multiparasitism with TC on the host A. pernyi. We observed lower percentages of multiparasitism in treatments where newly emerged and young TO females were used for parasitizing A. pernyi eggs with TC, and higher percentages of multiparasitism were observed when TO females were 3- and 4-day-old (postemergence). It means that young TO females did not parasitize as many eggs as older females. These results match with those of Pizzol et al. (2012), who tested different ages $T$. cacoeciae Marchal adult females parazitizing eggs of Lobesia botrana Denis and Schiffermüller (Lepidoptera: Tortricidae). Their results showed that parasitoid ages had impact on parasitism, as 1-day-old females produced fewer parasitized eggs than 2, 3, and 4-day-old females. In our experiments, we observed a strong choosiness behavior in young TO females on A. pernyi host. Young TO females did not show strong attractiveness toward $A$. pernyi eggs, notably the newly emerged females. This behavior may be due to the low ovarian load in the young TO females. Trichogramma ostriniae are among syn-ovigenic parasitoids exhibiting few mature eggs in ovaries after eclosion (Chen et al. 2005). Papaj (2000) reported that low egg load in early age of parasitoids is often responsible for high choosiness behavior during encountering hosts. We noticed that TO females deprived for 3 and 4 days from parasitization of $A$. pernyi host, severely attacked $A$. pernyi host after provision for parasitism and did not show strong choosiness behavior. This behavior suggest that these older TO females had high ovarian load. Barnay et al. (1999) reported that T. cacoeciae foraging activity was influenced by ovarian load, and that it could lead to a higher discovery rate in case of older T. cacoeciae females (when compared to younger females). The old parasitoid females had higher ovarian pressure because of inhibiting high number of mature eggs in ovaries, which consequently resulted into weaker choosiness behavior toward host (Klomp et al. 1980). Other factors such as endogenous circadian rhythm (Wang et al. 2019), 
temperature (Pizzol et al. 2010), or plants of targeted hosts (Thiery and Desneux 2018) may also affect multiparasitism through modulating the oviposition behavior in Trichogramma parasitoids.

In parasitoids, fecundity usually shows a gradual increase until it reaches a maximum rate and then a gradual decrease occurs until reproduction ceases shortly before death (Jervis and Kidd 1996; Pizzol et al. 2012; Biondi et al. 2013). Hegazi and Khafagi (2001) reported that efficiency of parasitization by host-deprived females of $T$. cacoeciae varied with ages, where parasitization rate was higher for 1-5-dayold females than 6-day-old females on Sitotroga cerealella Olivier (Lepidoptera: Gelechiidae) eggs, and the parasitization rate then declined as the females aged. Similarly, in our study, a drastic decline in parasitism rates (after a peak) was observed in the treatments where 5 and 6 days deprived TO females were used for parasitization of $A$. pernyi host with TC. We assumed that TO females deprived from $A$. pernyi host for such a long period of time (i.e., more than 4 days) resulted in intensive oosorption and consequently the parasitization ability of TO females decreased. The variation in multiparasitism rates in our results did confirm that parasitism ability of TO on A. pernyi host was largely age dependent (Fleury and Bouletreau 1993; Godfray 1994; Garcia et al. 2001; Makee 2005; Huang et al. 2017).

Moreover, comparison of percent emergence from $A$. pernyi host among treatments did not show any significant differences, likely because the same number of TC was offered in multiparasitism with TO in all the treatments. More specifically, the emergence rate was dependent on the competent parasitoid species (i.e. TC), as previously reported by studies on multiparasitism in Trichogramma parasitoids (Li et al. 2018; Iqbal et al. 2019). Trichogramma ostriniae species benefited using the emergence holes made by $T$. dendrolimi in $\mathrm{Li}$ et al. (2018) and T. leucaniae by TC (Iqbal et al. 2019). Furthermore, significant differences were found in emerged number of $\mathrm{TO}$ adults per egg. No TO individual wasp emerged per egg in the first treatment where TO females used for parasitization were 0.5 -day-old. By contrast, significantly more TO adults emerged per egg in the treatment where TO females used for parasitizing were 3-day-old. These results are consistent with that of Pizzol et al. (2012) where T. cacoeciae emergence increased according to ovipositing females age, with the highest emergence rate observed for 3-day-old females and the lowest emergence rate for 1-day-old females. It has been reported that when oviposition was prevented by host deprivation, T. cacoeciae and T. brassicae Bezdenko stored approximately twice as many eggs as found in newly emerged female (Volkoff and Daumal 1994). Our results showed that when host deprivation duration for TO was prolonged for 3 days, the parasitism ability and progeny production were markedly increased on $A$. pernyi host.
Screening of different wasp to wasp ratios of both Trichogramma species in multiparasitism on $A$. pernyi host

The percent multiparasitism in all the tested ratios was similar. High parasitism rates were observed because high densities of parasitoid wasps were offered in multiparasitism of A. pernyi eggs. Our results are in line with that of Huang et al. (2017) where increase in T. dendrolimi wasps to host eggs of $O$. furnacalis resulted in high parasitism rate. Watt et al. (2015) evaluated different ratios of parasitoid Spathius galinae Belokobylskij \& Strazanac (Hymenoptera: Braconidae) and its host Agrilus planipennis Fairmaire (Coleoptera: Buprestidae), and found that parasitism rate was positively associated with increasing parasitoid to host ratio. Because of the large size of host A. pernyi eggs, we offered high densities of parasitoid wasps. Indeed, eggs of the factitious host A. pernyi are large enough for multiple Trichogramma parasitoids to develop (having approximate $3180 \mu \mathrm{m}$ length and $2684 \mu \mathrm{m}$ width, Iqbal et al. 2019).

Biological parameters such as emergence, number of dead TO adults per egg, number of immature pupae (unidentified) and number of emergence holes per host egg varied among the tested TO:TC ratios. We found that the optimal wasp to wasp ratio was 15:10 (TO:TC) when they were offered for parasitization of $5 \mathrm{~A}$. pernyi eggs under laboratory conditions. Therefore, the optimal ratio of multiparasitism of TO:TC to host eggs of A. pernyi for being used for mass production is likely close to $3: 2: 1$. We assumed that optimal emergence of TO adults, low number of dead TO adults per egg, and high number of emergence holes per egg in the ratio of 3:2 (TO:TC) was likely due to a low interspecific intrinsic competition in $A$. pernyi egg at such ratio. Trichogramma chilonis did not perform more aggressively in our present study of multiparasitism on A. pernyi eggs as $T$. dendrolimi did in previously reported study of $\mathrm{Li}$ et al. (2018). Such low aggressiveness of TC in multiparasitism conditions may facilitate the emergence of TO adults from $A$. pernyi egg. Indeed, TC does not show strong specificity to A. pernyi as host, when compared to $T$. dendrolimi, and therefore, only few strains of TC can be reared on using this host (Hassan et al. 2004; Huang et al. 2013; Hou et al. 2018). Similar results were found when studying multiparasitism of TC and T. leucaniae on A. pernyi egg (Iqbal et al. 2019). Shi and Liu (2003) stressed that multiparasitism could help different parasitoids to use same host resources more effectively. Within-host competition among gregarious parasitoids that can also result in the phenomenon of 'resource sharing' in which adults from both species can emerge from the same multiparasitized hosts (Magdaraog et al. 2012). We also suspect that severe intrinsic competition occurred inside $A$. pernyi host in some of the tested ratios, i.e., 2:1 (TO:TC) and 5:1 (TO:TC), which resulted notably in high number of 
dead TO adults inside host egg, and low number of emergence holes on host egg surface. So, it is notable that these limitations could result from the high population densities of maternal parasitoid during parasitism of A. pernyi eggs. A similar conclusion was reached by Hassan et al. (2004) for T. dendrolimi, TC, T. cacoeciae, and T. embryophagum developping on A. pernyi host: occurence of high levels of superparasitism could result in low emergence rate, and high number of dead larvae, pupae and adults inside $A$. pernyi egg. Han et al. (1993) reported that interspecific competition could decrease the survivorship of one or more parasitoid species in multiparasitism. An optimal parasitoid to host ratio is one of the most important prerequisites in mass production of parasitoids (Wei et al. 2016). Moreover, the total number of parasitoids of both species emerging from the same egg of $A$. pernyi did not show any significant differences. Antheraea pernyi eggs could enable producing 50 to $260 \mathrm{~T}$. dendrolimi, TC or T. leucaniae per individual host egg, but mostly about 60-70 Trichogramma adults often develop in each A. pernyi egg (Wang et al. 1998, 2014; Liu et al. 2000; Huang et al. 2013; Zang 2015; Iqbal et al. 2019).

The pre-emergence time for the offspring of both species did not show significant differences. The offspring of both species emerged at the same time (day) from A. pernyi eggs. We considered that TO completed its development inside A. pernyi egg faster because of multiparasitism with TC. Previous study by Li et al. (2018) reported that the pre-emergence time for TO was 17 days in monoparasitism whereas it decreased to 12 days in multiparasitism conditions (with $T$. dendrolimi). These changes in the pre-emergence time could be considered as an advantage of multiparasitism technique on A. pernyi host which could ensure the availability of two different parasitoid species at a same time in field.

Inundative releasing of parasitoids against insect pests depends on their cost-effective mass rearing (Wei et al. 2016; Khanzada et al. 2019; Morais et al. 2019; Picciau et al. 2019; Suarez et al. 2019; Zang et al. 2021), aside their compatibility with other management methods potentially also used in Integrated Pest Management systems and/or in oganic farming (e.g. Kogan 1998; Desneux et al. 2007; Ragsdale et al. 2011; Biondi et al. 2018; Mohammed et al. 2018). From all above discussed results, we could conclude that the parasitism ability of TO on A. pernyi host is largely age dependent, i.e., TO females deprived from parasitism activity for 3 days (postemergence) not only could parasitize $A$. pernyi host in large amount but also can emerge successfully in optimum number in multiparasitism with TC. Our present study provided useful information on the biology of TO on A. pernyi host under multiparasitism. However, further evaluation of environmental conditions, wasp longevity, fecundity and fitness parameters of Trichogramma parasitoids produced through multiparasitism technique will need to be studied in detail for effective practical developments.

\section{Author contributions}

AI, ND and LSZ conceived and designed research. AI, YYH and YMC conducted experiments. AI analyzed data. AI, AA, LSM and LSZ wrote the manuscript.

Acknowledgements This research was funded by the National Key R\&D Program of China (2017YFD0201000) and the National Natural Science Foundation of China (31901946 and 31572058).

\section{Compliance with ethical standards}

Conflict of interest The authors declare no conflicts of interest.

\section{References}

Ayvaz A, Karasu E, Karaborklu S, Tuncbilek AS (2008) Effect of cold storage, rearing temperature, parasitoid age and irradiation on the performance of Trichogramma evanescens Westwood (Hymenoptera: Trichogrammatidae). J Stored Prod Res 44:232-240

Barnay O, Pizzol J, Gertz C, Kienlen JC, Hommay G, Lapchin L (1999) Host density dependence of discovery and exploitation rates of egg patches of Lobesia botrana (Lepidoptera: Tortricidae) and Ephestia kuehniella (Lepidoptera: Pyralidae) by the parasitoid Trichogramma cacoeciae (Hymenoptera: Trichogrammatidae). J Econ Entomol 92:1311-1320

Biondi A, Desneux N, Amiens-Desneux E, Siscaro G, Zappalà L (2013) Biology and Developmental Strategies of the Palaearctic Parasitoid Bracon nigricans (Hymenoptera: Braconidae) on the Neotropical Moth Tuta absoluta (Lepidoptera: Gelechiidae). J Econ Entomol 106:1638-1647

Biondi A, Guedes RNC, Wan FH, Desneux N (2018) Ecology, worldwide spread and management of the invasive South American tomato pinworm, Tuta absoluta: past, present and future. Annu Rev Entomol 63:239-258

Cabello T, Gamez M, Torres A, Garay J (2011) Possible effects of inter-specific competition on the coexistence of two parasitoid species: Trichogramma brassicae Bezdenko and Chelonus oculator (F.) (Hymenoptera: Trichogrammatidae, Braconidae). Community Ecol 12:78-88

Chailleux A, Biondi A, Han P, Tabone E, Desneux N (2013) Suitability of the pest-plant system Tuta absoluta (Lepidoptera: Gelechiidae) - tomato for Trichogramma (Hymenoptera: Trichogrammatidae) parasitoids and insights for biological control. Econ Entomol 106:2310-2321

Chen KW, Liu HZ, He YR (2005) The relationship between fecundity and female age of Trichogramma ostriniae Pang et Chen. Acta Entomol Sin 48:712-717

Cusumano A, Peri E, Vinson SB, Colazza S (2012) Interspecific extrinsic and intrinsic competitive interactions in egg parasitoids. Biocontrol 57:719-734

Cusumano A, Peri E, Colazza S (2016) Interspecific competition/facilitation among insect parasitoids. Curr Opin Insect Sci 14:12-16

Desneux N, Decourtye A, Delpuech JM (2007) The sublethal effects of pesticides on beneficial arthropods. Annu Rev Entomol 52:81-106 
Desneux N, Barta RJ, Delebecque CJ, Heimpel GE (2009) Transient host paralysis as a means of reducing self-superparasitism in koinobiont endoparasitoids. J Insect Physiol 55:321-327

Du WM, Xu J, Hou YY, Lin Y, Zang LS, Yang X, Zhang JJ, Ruan CC, Desneux N (2017) Trichogramma parasitoids can distinguish between fertilized and unfertilized host eggs. J Pest Sci 91:771-780

Fleury F, Bouletreau M (1993) Effect of temporary host deprivation on reproductive potential of Trichogramma brassicae. Entomol Exp Appl 68:203-210

Garcia P, Wajnberg E, Oliveira L, Tavares J (2001) Is the parasitization capacity of Trichogramma cordubensis influenced by the age females? Entomol Exp Appl 98:219-224

Gardner F, Wright MG, Kuhar TP, Pitcher SA, Hoffmann MP (2012) Dispersal of Trichogramma ostriniae in field corn. Biocontrol Sci Technol 22:1221-1233

Godfray HCJ (1994) Parasitoids: behavioral and evolutionary ecology. Princeton University Press, Chichester

Guo XJ, Di N, Chen X, Zhu Z, Zhang F, Tang B et al (2019) Performance of Trichogramma pintoi when parasitizing eggs of the oriental fruit moth Grapholita molesta. Entomol Gen 39:239-249

Han SC, Chen QX, Liu WH, Zhang ML (1993) Studies on interspecific competition between Anastatus japonicus and Trichogramma dendrolimi on host eggs. Nat Enem Insect 15:10-13

Harvey JA, Gols R, Strand MR (2009) Intrinsic competition and its effects on the survival and development of three species of endoparasitoid wasps. Entomol Exp Appl 130:238-248

Harvey JA, Poelman EH, Tanaka T (2013) Intrinsic inter- and intraspecific competition in parasitoid wasps. Annu Rev Entomol 58:333-351

Hassan SA, Liscsinszky H, Zhang G (2004) The oak-silkworm egg Antheraea pernyi (Lepidoptera: Anthelidae) as a mass rearing host for parasitoids of the genus Trichogramma (Hymenoptera: Trichogrammatidae). Biocontrol Sci Technol 14:269-279

Hegazi EM, Khafagi WE (2001) Pattern of Egg Management by Trichogramma cacoeciae and T. dendrolimi (Hymenoptera: Trichogrammatidae). Biocontrol Sci Technol 11:353-359

Hohmann CL, Luck RF (2004) Effect of host availability and egg load in Trichogramma platneri Nagarkatti (Hymenoptera: Trichogrammatidae) and its consequences on progeny quality. Braz Arch Biol Technol 47:413-422

Hou YY, Yang XB, Zang LS, Zhang C, Lucie M, Nicolas D (2018) Effect of oriental armyworm Mythimna separata egg age on the parasitism and host suitability for five Trichogramma species. J Pest Sci 91:1181-1189

Huang SS, Zang LS, Ruan CC (2013) Parasitization ecology, mass production, and application of Trichogramma. Science Press, Beijing, pp 116-140

Huang J, Hua HQ, Wang LY, Zhang F, Li YX (2017) Number of attacks by Trichogramma dendrolimi (Hymenoptera: Trichogrammatidae) affects the successful parasitism of Ostrinia furnacalis (Lepidoptera: Crambidae) eggs. Bull Entomol Res 107:812-819

Iqbal A, Chen YM, Hou YY, Zhang L, Desneux N, Zang LS (2019) Factitious host species outcome of multiparasitism between egg parasitoids. J Pest Sci 92:1261-1269

Jervis MA, Kidd NAC (1996) Parasitoid adult feeding ecology and biocontrol. A review. Biocontrol News Inf 16:11-26

Jervis MA, Heimpel GE, Ferns PN, Harvey JA, Kidd NA (2001) Lifehistory strategies in parasitoid wasps: a comparative analysis of 'ovigeny'. J Anim Ecol 70:442-458

Keinan Y, Kishinevsky M, Segoli M, Keasar T (2012) Repeated probing of hosts: an important component of superparasitism. Behav Ecol 23:1263-1268

Khanzada MS, Wang S, Huang NX, Pang H, Tan XL, Khanzada SR, (2019) Optimization of microencapsulated artificial diets for mass rearing of the predacious big eyed bug, Geocoris pallidipennis. Entomol Gen 39:353-363

Klomp H, Teerink B, Wei CM (1980) Discrimination between parasitized and unparasitized hosts in the egg parasite Trichogramma embryophagum (Hym.: Trichogrammatidae): a matter of learning and forgetting. Neth J Zool 30:254-277

Kogan M (1998) Integrated Pest Management: historical perspectives and contemporary developments. Annu Rev Entomol 43:243-270

Li TH, Tian CY, Zang LS, Hou YY, Ruan CC, Yang XB, Lucie M, Desneux N (2018) Multiparasitism with Trichogramma dendrolimi on egg of Chinese oak silkworm, Antheraea pernyi, enhances emergence of Trichogramma ostriniae. J Pest Sci 92:707-713

Li XY, Lei Q, Hua HQ, Song HF, Wang Su et al (2019) Impact of host suitability on oviposition preference toward fertilized and unfertilized host eggs in two Trichogramma parasitoid species. Entomol Gen 39:313-323

Liu SS, Zhang GM, Zhang F (1998) Factors influencing parasitism of Trichogramma dendrolimi on eggs of the Asian corn borer, Ostrinia furnacalis. Biocontrol 43:273-287

Liu ZC, Liu JF, Zhang F, Li DS, Feng XX (2000) Production and field application techniques of Trichogramma. Golden Shield Press, Beijing

Magdaraog PM, Harvey JA, Tanaka T, Gols R (2012) Intrinsic competition among solitary and gregarious endoparasitoid wasps and the phenomenon of 'resource sharing'. Ecol Entomol 37:65-74

Makee H (2005) Effects of repeated and delayed exposure to codling moth eggs on reproduction of Trichogramma cacoeciae and Trichogramma principium (Hymenoptera: Trichogrammatidae) females. J Pest Sci 78:83-89

Mandour NS, Mahmoud MF, Osman MAN, Qiu B (2008) Efficiency, intrinsic competition and interspecific host discrimination of Copidosoma desantisi and Trichogramma evanescens, two parasitoids of Phthorimaea operculella. Biocontrol Sci Technol 18:903-912

Mohammed AAH, Desneux N, Fan YJ, Han P, Ali A, Song DL, Gao XW (2018) Impact of imidacloprid and natural enemies on cereal aphids: integration or ecosystem service disruption? Entomol Gen 37:47-61

Morais WCC, Plata-Rueda A, Martínez LC, Zanuncio AJV, Fernandes FL et al (2019) Potential of Diaphania hyalinata and Tenebrio molitor as alternative host for mass rearing of Palmistichus elaeisis (Hymenoptera: Eulophidae). Entomol Gen 39:285-294

Papaj DR (2000) Ovarian dynamics and host use. Annu Rev Entomol 45:423-448

Picciau L, Alma A, Ferracini C (2019) Effect of different feeding sources on lifespan and fecundity in the biocontrol agent Torymus sinensis. Biol Control 134:45-52

Pinto JD (1992) Novel taxa of Trichogramma from the New World tropics and Australia (Hymenoptera: Trichogrammatidae). J N Y Entomol Soc 100:621-633

Pizzol J, Desneux N, Wajnberg E, Thiéry D (2012) Parasitoid and host egg ages have independent impact on various biological traits in a Trichogramma species. J Pest Sci 85:489-496

Pizzol J, Pintureau B, Khoualdia O, Desneux N (2010) Temperaturedependent differences in biological traits between two strains of Trichogramma cacoeciae (Hymenoptera: Trichogrammatidae). J Pest Sci 83:447-452

Ragsdale DW, Landis DA, Brodeur J, Heimpel GE, Desneux N (2011) Ecology and management of the soybean aphid in North America. Annu Rev Entomol 56:375-399

Reznik SY, Voinovich ND, Umarova TY (2001) Comparative behavioral analysis of ovipositing females and females with egg retention in Trichogramma principium Sug. et Sor. (Hymenoptera, Trichogrammatidae). Entomol Rev 81:895-903

SAS Institute (2010) SAS/STAT v.9.1. SAS Institute, Cary, NC, USA 
Shi ZH, Liu SS (2003) Interspecific interactions between Cotesia plutellae and Oomyzus sokolowskii, two major parasitoids of diamondback moth, Plutella xylostella. Chin J Appl Ecol 14:949-954

Smith SM (1996) Biological control with Trichogramma: advances, successes, and potential of their use. Annu Rev Entomol 41:375-406

Stouthamer R, Hu J, van Kan FJPM, Platner GR, Pinto JD (1999) The utility of internally transcribed spacer 2 DNA sequences of the nuclear ribosomal gene for distinguishing sibling species of Trichogramma. Biocontrol 43:421-440

Suarez L, Biancheri MJB, Sanchez G, Murua F, Funes CF et al (2019) Effects of releasing two Diachasmimorpha longicaudata population lines for the control of Ceratitis capitata infesting three key host fruit species. Biol Control 133:58-65

Tabone T, Bardon C, Desneux N, Wajnberg E (2010) Comparative assessment of parasitism of different Trichogramma spp. on Plutella xylostella L. on greenhouse cauliflower. J Pest Sci 83:251-256

Thiery D, Desneux N (2018) Host plants of the polyphagous grapevine moth Lobesia botrana during larval stage modulate moth egg quality and subsequent parasitism by the parasitoid Trichogramma cacoeciae. Entomol Gen 38:47-59

Velzen EV, Vila SP, Etienne RS (2016) The role of within-host competition for coexistence in multiparasitoid-host systems. Am Nat $87: 48-59$

Volkoff AN, Daumal J (1994) Ovarian cycle in immature and adult stages of Trichogramma cacoeciae and Trichogramma brassicae (Hym., Trichogrammatidae). Entomophaga 39:303-312

Wang CL, Zhang J, Huo ST (1998) Study, reproduction and utilization of Trichogramma. In: Bao JZ, Gu DX (eds) Biological control in China. Shanxi Science and Technology Press, Taiyuan, pp 67-123

Wang ZY, Lu X, He KL, Zhou DR (2000) Review of history, present situation and prospect of the Asian maize borer research in China. J Shenyang Agric Univ 31:402-412

Wang ZY, He KL, Yan S (2005) Large-scale augmentative biological control of Asian corn borer using Trichogramma in China: a success story. In: Conference paper: second international symposium on biological control of arthropods, Davos, Switzerland, pp 487-494

Wang ZY, He KL, Zhang F, Lu X, Babendreier D (2014) Mass rearing and release of Trichogramma for biological control of insect pests of corn in China. Biol Control 68:136-144
Wang Y, Xiang M, Hou YY, Yang X, Dai H et al (2019) Impact of egg deposition period on the timing of adult emergence in Trichogramma parasitoids. Entomol Gen 39:339-346

Watt TJ, Duan JJ, Tallamy DW, Goldstein JH (2015) Effect of parasitoid: host ratio and group size on fitness of Spathius galinae (Hymenoptera: Braconidae): implications for mass-rearing. J Econ Entomol 108:951-956

Wei K, Gao SK, Tang YL, Wang XY, Yang ZQ (2016) Determination of the optimal parasitoid-to-host ratio for efficient mass-rearing of the parasitoid, Sclerodermus pupariae (Hymenoptera: Bethylidae). J Appl Entomol 141:181-188

Wu H, Huang YC, Guo JX, Liu JB, Lai XS et al (2018) Effect of cold storage of Corcyra cephalonica eggs on the fitness for Trichogramma chilonis. Biol Control 124:40-45

Yamamoto D, Henderson R, Corley LS, Iwabuchi K (2007) Intrinsic, inter-specific competition between egg, egg-larval, and larval parasitoids of plusiine loopers. Ecol Entomol 32:221-228

Yuan XH, Song LW, Zhang JJ, Zang LS, Zhu L, Ruan CC, Sun GZ (2012) Performance of four Chinese Trichogramma species as biocontrol agents of the rice striped stem borer, Chilo suppressalis, under various temperature and humidity regimes. J Pest Sci $85: 497-504$

Zang LS (2015) Mass production of Trichogramma dendrolimi using eggs of Antheraea pernyi, and field application in the suppression of Ostrinia furnacalis in Jilin Province, China. IOBC News1 98:9

Zang LS, Wang S, Zhang F, Desneux N (2021) Biological control with Trichogramma in China: history, present status and perspectives. Annu Rev Entomol. https://doi.org/10.1146/annurev-ento-06012 0-091620

Zhang JJ, Desneux N, Benelli G, Zang LS, Du WM, Ruan CC (2017) Geographic variation of diapause induction rates in Trichogramma drendrolimi (Hymenoptera: Trichogrammatidae) in China. J Econ Entomol 110:386-391

Zhang JJ, Zhang X, Zang LS, Du WM, Hou YY, Ruan CC, Desneux N (2018) Advantages of diapause in Trichogramma dendrolimi mass production via eggs of the Chinese silkworm, Antheraea pernyi. Pest Manag Sci 74:959-965

Publisher's Note Springer Nature remains neutral with regard to jurisdictional claims in published maps and institutional affiliations. 